Article

\title{
Effects of the Selected Point of Voltage Reference on the Apparent Power Measurement in Three-Phase Star Systems
}

\author{
Vicente León-Martínez ${ }^{\circledR}$, Joaquín Montañana-Romeu*® Elisa Peñalvo-López® and \\ Carlos M. Álvarez-Bel ${ }^{(1)}$ \\ Electrical Engineering Department, Universitat Politècnica de València, Camino de Vera 14, \\ 46022 València, Spain; vleon@die.upv.es (V.L.-M.); elpealpe@upvnet.es (E.P.-L); calvarez@die.upv.es (C.M.Á.-B.) \\ * Correspondence: jmontanana@die.upv.es;Tel.: +34-963879594
}

Received: 2 January 2020; Accepted: 2 February 2020; Published: 4 February 2020

\begin{abstract}
The phenomenon responsible for the different apparent powers measured in a subsystem of a three-phase star-configured system, based on the voltage reference point, was identified in this paper using specific components of the instantaneous powers, as a result of applying the conservation of energy principle to the entire system. The effects of the phenomenon were determined using a proposed apparent power component referred to as the neutral-displacement power, whose square is the quadratic difference between the apparent powers of a subsystem, measured using two voltage reference points. The neutral-displacement power is a component of the apparent power, which is determined using the values of the zero-sequence voltages and the line currents in that subsystem. Expressions of the proposed power were derived using the Buchholz apparent power formulations. The validation of the derived expressions was checked in the laboratory and in a real-world electrical network, using a well-known commercial analyzer and a prototype developed by the authors.
\end{abstract}

Keywords: apparent power; power measurement; instrumentation; neutral-displacement power; neutral-point displacement voltage; power system

\section{Introduction}

In electrical power instrumentation, the apparent power measured by a power analyzer placed at the point of common coupling (PCC) of two subsystems of a three-phase power system (Figure 1) generally varies with the selected voltage reference point, a neutral point $(\mathrm{N})$ of subsystem 1 , a neutral point (n) of subsystem 2, or a grounding (earthing) point (G). This phenomenon is relevant when measuring, for example, the apparent power of one of the subsystems and the corresponding neutral point ( $\mathrm{N}$ or $\mathrm{n}$ ) is not accessible, such as may occur in a star-connected three-phase motor with only three terminals, or when the neutral points are far from the measurement point. 


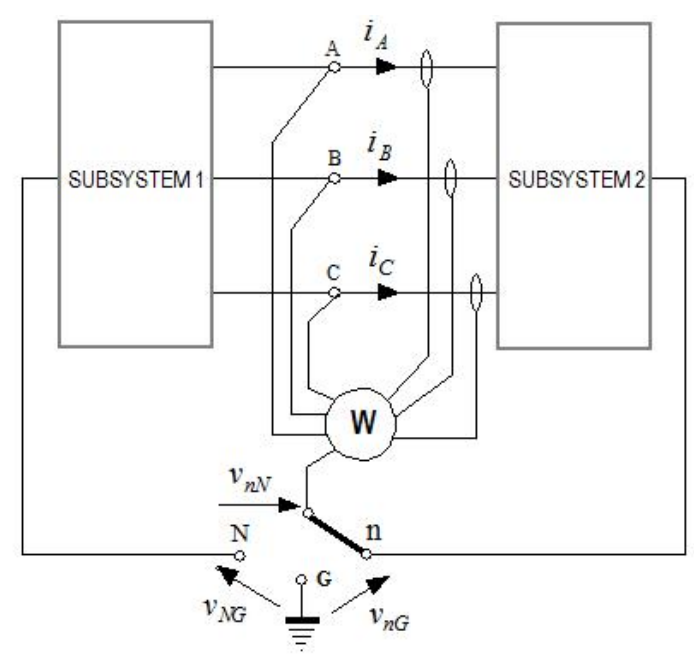

Figure 1. Voltage reference points for apparent power measurement.

The apparent power of any part of a power system is, in our opinion, a formal quantity that measures the combined effects of all the power phenomena in that part of the system. Hence, when a power analyzer registers different values of the apparent power at the PCC of two directly connected subsystems (Figure 1) based on the use of different voltage reference points, it suggests the existence of various power phenomena with effects derived from the voltage reference point. Therefore, if both subsystems in Figure 1 are star-connected with neutral points $\mathrm{N}$ and $\mathrm{n}$, the power analyzer would register the apparent power of subsystem 1 if $\mathrm{N}$ is used as the voltage reference point, and that of subsystem 2 if $n$ is used as the voltage reference point. If the grounding point $G$ is used as the voltage reference, the apparent power registered by the power analyzer would not be that of either subsystem.

Investigating the phenomenon associated with the above effect of the voltage reference point, it should be noted that, when the power system in Figure 1 is sinusoidal and balanced, the apparent powers measured at the PCC of the two subsystems are independent of the point of voltage reference $(\mathrm{N}, \mathrm{n}$, or $\mathrm{G})$. This is because the reference points would have the same voltage. However, when subsystems are unbalanced and/or distorted, there would be voltage differences between the above three points [1,2], resulting in differing apparent powers measured when using them as the voltage reference points. Since voltage differences between the different reference points are the neutral-point displacement voltages [3], the neutral displacement phenomenon is responsible for the different values of the measured apparent powers, according to the voltage reference point. The manifestation of over-voltages and sub-voltages is the main known effect of this phenomenon.

The neutral-point displacement is a well-known phenomenon in power systems since the early 20th century. Boyajian and McCarthy [4] explained in 1931 the neutral displacement phenomenon, which they referred to as neutral inversion. Additionally, Gates [5] analyzed in 1936 the phenomenon caused by open circuits in power systems grounded through neutral earthing transformers and Petersen coils. Many works found in the technical literature deal with the problems caused by the phenomenon of neutral displacement in grounded systems [6-12]. Thus, several procedures of detection $[13,14]$ and correction $[15,16]$ of the neutral displacement phenomenon were developed over time.

The effects caused by the neutral-point displacement voltages were also studied in power systems with compensating capacitor banks [17-19]. However, we did not find applications of the neutral displacement phenomenon to power measurement in power systems, perhaps because the power effects of this phenomenon are not so well known and, on many occasions, they are confused with the apparent power in the neutral conductor impedance. Indeed, all the above studies focused on measuring and reducing the neutral displacement voltages, but the powers associated with the neutral displacement phenomenon were not formulated until now. 
Thus, the main novelty of this paper is to define the power expressions that measure the effects of the neutral displacement phenomenon and apply them to the power measurement area. These powers are defined in this paper under the consideration that the neutral-point displacement is able to manifest energies, not only voltages, in powers systems, which were identified in specific components of the source and load instantaneous powers as a result of applying the conservation of energy principle to a three-phase star-configured power system, as described in Section 2 of this paper.

The effects of the energies caused by the neutral displacement phenomenon were eliminated in the pass by many commercial power analyzers, using the line-to-line voltages instead of the line-to-neutral (or line-to-earth) voltages in the measurement of the apparent powers, in order to avoid variations derived from the voltage reference point. In our opinion, this solution engenders errors on the values of the apparent powers. Fortunately, this solution is not currently used by the main commercial instrumentation manufacturers, which allow the users to select the point of voltage reference, even including grounded points. Thus, in Section 3, we examined the effects of the neutral displacement phenomenon on the values of the apparent powers of star-configured sources and loads using a proposed power that we refer to as the neutral-displacement power $\left(S_{n}\right)$. In the present work, the square of the neutral-displacement power is defined for each part of a three-phase power system as the difference between the squares of the apparent powers of that part of the system measured using two different voltage reference points. This definition was used to derive expressions of the neutral-displacement power and its components using the well-known power formulation approach proposed by Buchholz [20], which is the base of a few commercial power analyzers. Hence, the explanation of the different values of apparent powers measured by the power analyzers depending on the selected point of voltage reference can be considered as an application of the neutral displacement phenomenon. Although the proposed power is used in a granted patent [21] and the neutral-point displacement voltage is a well-known phenomenon, the neutral-displacement power is not included in any standard $[3,22,23]$ and it is not established by major approaches such as those described in References [24-29].

The derived neutral-displacement power expressions were experimentally verified in a laboratory and using an actual installation of an electric company, as described in Section 4. The experiments were carried out using the commercial power analyzer Fluke 437 Series II and our prototype power analyzer SIMPELEC [30], which measures the apparent power according to the Buchholz approach, as well as the proposed neutral-displacement power, more recently incorporated. The conclusions drawn from the present study are finally presented in Section 5 .

\section{Power Phenomenon Associated with the Voltage Reference Point in a Three-Phase Star-Configured System}

This section demonstrates how the phenomenon of the displacement of the neutral point manifests energies in the power systems, which are finally responsible for the variation of the measured apparent power of a given part of a power system with the voltage reference point.

\subsection{Use of Source and Load Neutral Points as Voltage Reference Points}

Let us consider the three-phase four-wire power system illustrated in Figure 2. If at least one of its subsystems, the source or load, is unbalanced and/or distorted and the neutral conductor impedance is not negligible, a voltage drop could occur between the source and load neutral points ( $\mathrm{N}$ and $\mathrm{n}$ ), the value of which can be determined using Kirchhoff's second law. This voltage is the neutral-point displacement voltage [3] and is responsible for the variation of the measured source and load instantaneous powers with the voltage reference point. 


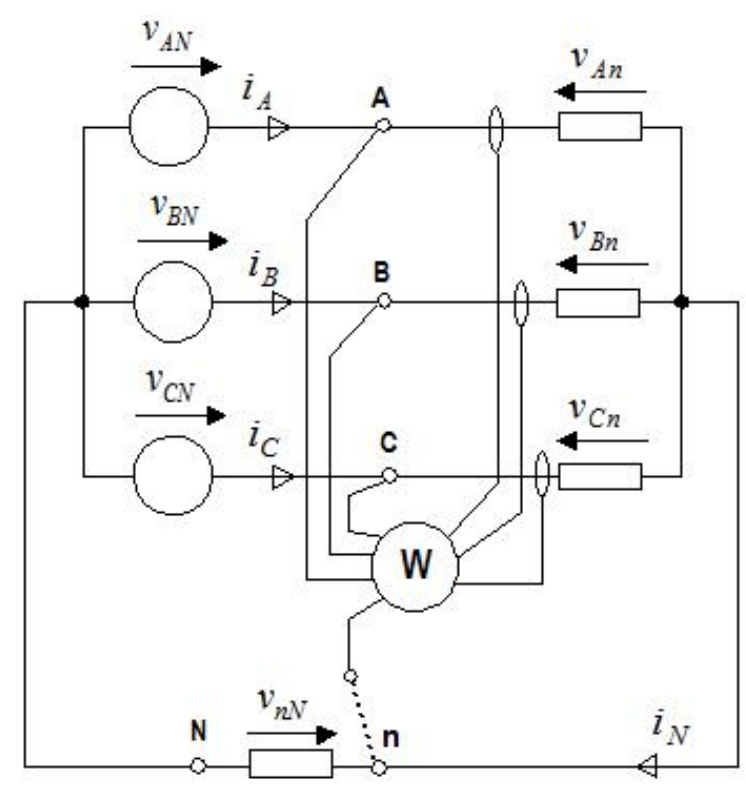

Figure 2. Power analyzer with the load neutral point as the voltage reference point.

The load instantaneous power of the system in Figure 2 can be expressed as follows:

$$
p_{l}(t)=v_{A n} i_{A}+v_{B n} i_{B}+v_{C n} i_{C} .
$$

The value given by Equation (1) would be registered by a power analyzer placed at the PCC (A, B, or $C$ ) of the system in Figure 2 if the load neutral point (n) is used as the voltage reference. According to Kirchhoff's second law, the line-to-neutral instantaneous voltages in the load phases $\left(v_{A n}, v_{B n}\right.$, and $\left.v_{C n}\right)$ can be expressed as functions of the source line-to-neutral instantaneous voltages $\left(v_{A N}, v_{B N}\right.$, and $\left.v_{C N}\right)$ and the neutral-point displacement voltage $\left(v_{n N}\right)$, as follows:

$$
\begin{aligned}
& v_{A n}=v_{A N}-v_{n N}, \\
& v_{B n}=v_{B N}-v_{n N}, \\
& v_{C n}=v_{C N}-v_{n N} .
\end{aligned}
$$

From Equations (1) and (2), we obtain

$$
p_{l}(t)=v_{\mathrm{AN}} i_{A}+v_{\mathrm{BN}} i_{B}+v_{\mathrm{CN}} i_{C}-v_{\mathrm{nN}} \cdot\left(i_{A}+i_{B}+i_{C}\right) .
$$

According to Fortescue's theorem [31], the neutral-point displacement instantaneous voltage can be expressed as the difference between the zero-sequence line-to-neutral instantaneous voltages of the source $\left(v_{A N 0}\right)$ and load $\left(v_{A n 0}\right)$,

$$
v_{n N}=v_{A N 0}-v_{A n 0}
$$

both for the fundamental frequency and harmonics, i.e.,

$$
v_{A N 0}=\frac{1}{3} \sum_{x=1}^{\infty}\left(v_{A N x}+v_{B N x}+v_{C N x}\right) \quad v_{A n 0}=\frac{1}{3} \sum_{y=1}^{\infty}\left(v_{A n y}+v_{B n y}+v_{C n y}\right) .
$$

The load instantaneous power can, thus, be expressed as

$$
p_{l}(t)=v_{A N} i_{A}+v_{B N} i_{B}+v_{C N} i_{C}+\left(v_{A n 0}-v_{A N 0}\right) \cdot\left(i_{A}+i_{B}+i_{C}\right)=p_{s}(t)+p_{n}(t) .
$$


The first three terms in Equation (6) represent the source instantaneous power.

$$
p_{s}(t)=v_{A N} i_{A}+v_{B N} i_{B}+v_{C N} i_{C} .
$$

The value given by Equation (6) would be registered by a power analyzer placed at a PCC of the system in Figure 2 if the source neutral point $(N)$ is used as the voltage reference point.

Because the voltage $v_{n N}$, given by Equation (4), determines the displacements of the source and load neutral points [3], the term in Equation (6),

$$
p_{n}(t)=\left(v_{A n 0}-v_{A N 0}\right) \cdot\left(i_{A}+i_{B}+i_{C}\right)=p_{l}(t)-p_{s}(t),
$$

should be the neutral-displacement instantaneous power, which defines the load and source instantaneous power differences. This power is necessary to satisfy the conservation of energy principle and identifies the phenomenon associated with the variation of the apparent power measured by a power analyzer with the voltage reference point ( $\mathrm{n}$ or $\mathrm{N}$ ).

From Equation (8), two components of the neutral-displacement instantaneous power can be defined, namely, the load component,

$$
p_{n l}(t)=v_{A n 0} \cdot\left(i_{A}+i_{B}+i_{C}\right),
$$

and the source component,

$$
p_{n s}(t)=v_{A N 0} \cdot\left(i_{A}+i_{B}+i_{C}\right) .
$$

These two components of the neutral-displacement instantaneous power satisfy the equation

$$
p_{n}(t)=p_{n l}(t)-p_{n s}(t)
$$

Hence, the instantaneous power difference between the source and load of the system in Figure 2 is exclusively due to the different neutral-displacement instantaneous powers of the two subsystems.

\subsection{Using a Grounding Point as the Voltage Reference Point}

This is the favored solution adopted and recommended by many manufacturers of power analyzers for situations in which either the load neutral point (n) or the source neutral point $(\mathrm{N})$ is not accessible.

The instantaneous power registered by a power analyzer placed at the PCC of the power system in Figure 3 when the grounding point $(\mathrm{G})$ is used as the voltage reference point can be expressed as follows:

$$
p_{p c c}(t)=v_{A G} i_{A}+v_{B G} i_{B}+v_{C G} i_{C} .
$$

The result of Equation (12) is different from the load and source instantaneous powers, in general. Hence, the absolute error of the measured load instantaneous power when the grounding point $(G)$ is used as the voltage reference point instead of the load neutral point (n) is given by

$$
p_{n l}^{G}(t)=p_{l}(t)-p_{p c c}(t)=\left(v_{A n 0}-v_{A G 0}\right) \cdot\left(i_{A}+i_{B}+i_{C}\right),
$$

where $v_{G n}=v_{A n 0}-v_{A G 0}$, according to Fortescue's theorem; the load zero-sequence voltages $\left(v_{A n 0}\right)$ are determined by Equation (5), and $v_{A G 0}$ is the zero-sequence component of the set $\left(v_{A G}, v_{B G}, v_{C G}\right)$. If the grounding point is ideal, $v_{A G 0}=0$, and Equation (13) can be simplified as

$$
p_{n l}^{G}(t)=v_{A n 0} \cdot\left(i_{A}+i_{B}+i_{C}\right)=p_{n l}(t) .
$$




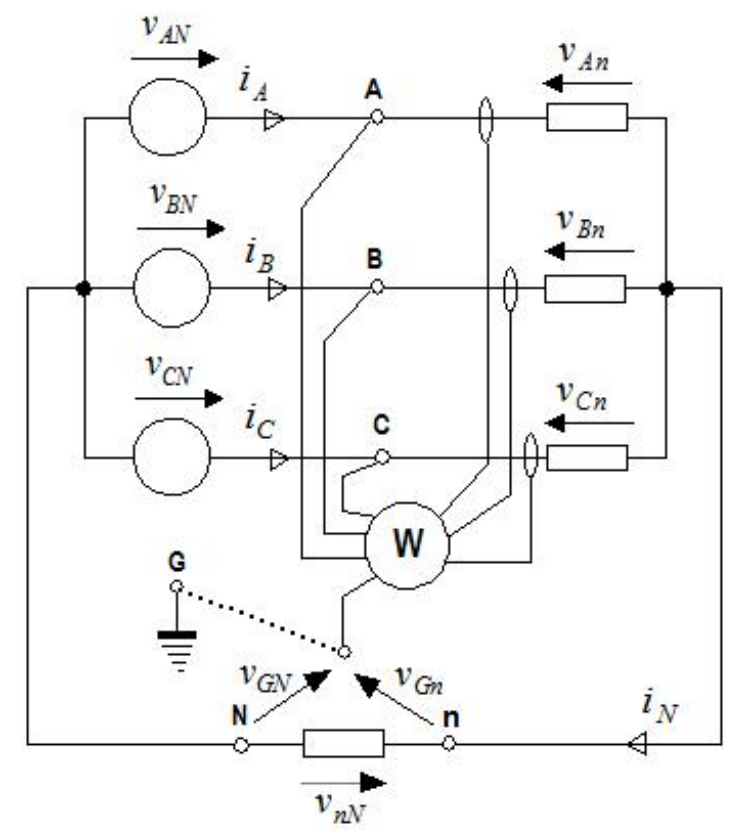

Figure 3. Power analyzer with the grounding point $(G)$ used as the voltage reference point.

Hence, the absolute error in measuring the load instantaneous power using an ideal grounding point as the voltage reference point is equal to the load component of the neutral-displacement instantaneous power.

Similarly, because $v_{G N}=v_{A N 0}-v_{A G 0}$, the absolute error of the measured source instantaneous power when the grounding point $(G)$ is used as the voltage reference point instead of the source neutral point $(N)$ is given by

$$
p_{n s}^{G}(t)=p_{s}(t)-p_{p c c}(t)=\left(v_{A N 0}-v_{A G 0}\right) \cdot\left(i_{A}+i_{B}+i_{C}\right),
$$

where the source zero-sequence voltage $\left(v_{A N O}\right)$ is determined by Equation (5). Likewise, if the grounding point $(G)$ is ideal, Equation (15) can be reduced to

$$
p_{n s}^{G}(t)=v_{A N 0} \cdot\left(i_{A}+i_{B}+i_{C}\right)=p_{n s}(t)
$$

Hence, the absolute error in measuring the source instantaneous power when the grounding point $(G)$ is used as the voltage reference point instead of the source neutral point $(N)$ is the source component of the neutral-displacement power.

From Equations (13) and (15), it can be noted that

$$
p_{n}(t)=p_{n l}^{G}(t)-p_{n s}^{G}(t)=p_{l}(t)-p_{s}(t)
$$

The neutral-displacement instantaneous power is the difference between the measurement errors of the load and source instantaneous powers when the voltage reference point is another point other than the load and source neutrals points, respectively.

\section{Apparent Power Difference Due to the Selected Voltage Reference Point: Neutral-Displacement Power}

Let us consider the three-phase four-wire power system shown in Figure 2, where a power analyzer is connected at the PCC between the source and load. It is well known that the values of the source and load apparent powers registered by the analyzer match the actual powers of the two 
subsystems when their neutral points ( $\mathrm{N}$ and $\mathrm{n}$ ) have the same voltage, as occurs when either the neutral conductor impedance is zero or the system is sinusoidal and balanced.

However, when the neutral conductor has impedance, a difference can be observed between the source and load apparent powers in unbalanced and/or distorted systems. This difference is due to the effects of the neutral displacement phenomenon and can be determined based on our proposed neutral-displacement power $\left(S_{n}\right)$. Using Buchholz's apparent powers [20], the square of this quantity must be, in our opinion, the quadratic difference between the load and source apparent powers $\left(S_{l}\right.$ and $\left.S_{s}\right)$,

$$
S_{n}^{2}=S_{l}^{2}-S_{s}^{2}
$$

The definition of the neutral-displacement power $\left(S_{n}\right)$ in Equation (18) is consistent with (1) the consideration of $S_{n}=0$ (i.e., $S_{l}=S_{s}$ ) when there is no displacement between the load and source neutral points, and (2) the apparent power is not a conservative quantity; then, the apparent powers of two or more subsystems cannot be arithmetically added or subtracted.

In this section, the expressions of the load and source neutral-displacement powers and their respective components are established using the apparent power expressions of Buchholz [20]. It should be noted that the expressions of the neutral-displacement powers derived from Buchholz's apparent powers are formally similar to the expressions of the neutral-displacement instantaneous powers established in Section 2.

\subsection{Neutral-Displacement Power Expression}

Buchholz's expressions of the apparent powers measured at the PCC of the load and source of the system in Figure 2, using the neutral points of the load (n) and source $(\mathrm{N})$ as voltage reference points, respectively, are as follows [20]:

$$
\begin{aligned}
& S_{l}=\sqrt{\left(V_{A n}^{2}+V_{B n}^{2}+V_{C n}^{2}\right) \cdot\left(I_{A}^{2}+I_{B}^{2}+I_{C}^{2}\right)}, \\
& S_{S}=\sqrt{\left(V_{A N}^{2}+V_{B N}^{2}+V_{C N}^{2}\right) \cdot\left(I_{A}^{2}+I_{B}^{2}+I_{C}^{2}\right)},
\end{aligned}
$$

where the sets $\left(V_{A n}, V_{B n}, V_{C n}\right)$ and $\left(V_{A N}, V_{B N}, V_{C N}\right)$ represent the root-mean-square (RMS) values of the load and source line-to-neutral voltages, respectively, and the set $\left(I_{A}, I_{B}, I_{C}\right)$ represents the RMS values of the line currents.

From Equations (18) and (19), we obtain

$$
S_{n}^{2}=\left[\left(V_{A n}^{2}+V_{B n}^{2}+V_{C n}^{2}\right)-\left(V_{A N}^{2}+V_{B N}^{2}+V_{C N}^{2}\right)\right] \cdot\left(I_{A}^{2}+I_{B}^{2}+I_{C}^{2}\right) .
$$

Equation (20) was applied to the following two well-known properties of Fortescue's theorem [31]:

(i) For the fundamental-frequency $(h=1)$ and each harmonic $(h \neq 1)$, the sum of the squares of the RMS line-to-neutral voltages satisfies

$$
V_{A h}^{2}+V_{B h}^{2}+V_{C h}^{2}=3 \cdot\left(V_{A h+}^{2}+V_{A h-}^{2}+V_{A h 0}^{2}\right),
$$

where the subscripts,+- , and 0 respectively indicate the positive-, negative-, and zero-sequence components.

(ii) The positive- and negative-sequence line-to-neutral voltages have the same values for directly connected loads and sources, i.e.,

$$
V_{A n+}=V_{A N+} \quad V_{A n-}=V_{A N-} .
$$

Based on the application, Equation (20) can be simplified as

$$
S_{n}^{2}=3 \cdot\left(V_{A n 0}^{2}-V_{A N 0}^{2}\right) \cdot\left(I_{A}^{2}+I_{B}^{2}+I_{C}^{2}\right),
$$


where $V_{A n 0}$ and $V_{A N 0}$ are the RMS values of the load and source zero-sequence line-to-neutral voltages, respectively, determined by the application of a Fourier series.

$$
V_{A n 0}=\sqrt{\sum_{y=1}^{\infty} V_{A n 0 y^{\prime}}^{2}} \quad V_{A N 0}=\sqrt{\sum_{x=1}^{\infty} V_{A N 0 x}^{2}} .
$$

It can be observed that Equations (18) and (23), which express the square of the neutral-displacement power, are formally similar to Equation (8). The similarities are as follows:

(a) The square of the neutral-displacement power relates the same quantities using the same terms as the neutral-displacement instantaneous power.

(b) Equation (8) involves the product of instantaneous voltages and currents, and Equation (23) involves the product of the squares of the same voltages and currents.

In our opinion, these similarities indicate that the neutral-displacement power $\left(S_{n}\right)$, determined by Equations (18) and (23), measures the effects of the neutral-point displacement phenomenon on the apparent powers, whereas Equation (8) identifies the phenomenon responsible for the effect.

According to Equations (18) and (24), the neutral-displacement power derived from Buchholz's apparent power can be expressed as follows:

$$
S_{n}=\sqrt{S_{l}^{2}-S_{s}^{2}}=\sqrt{3 \cdot\left(V_{A n 0}^{2}-V_{A N 0}^{2}\right) \cdot\left(I_{A}^{2}+I_{B}^{2}+I_{C}^{2}\right)} .
$$

Equation (25) indicates that two components of the neutral-displacement power can be defined, namely, the load component $\left(S_{n l}\right)$ and source component $\left(S_{n s}\right)$. The neutral-displacement power components satisfy

$$
S_{n}=\sqrt{S_{n l}^{2}-S_{n s}^{2}} .
$$

The first neutral-displacement power component,

$$
S_{n l}=V_{A n 0} \cdot \sqrt{3 \cdot\left(I_{A}^{2}+I_{B}^{2}+I_{C}^{2}\right)},
$$

is a measure of the portion of the load apparent power that is directly caused by the load neutral-point displacement with respect to an ideal voltage reference point. Similarly, the second neutral-displacement power component,

$$
S_{n s}=V_{A N 0} \cdot \sqrt{3 \cdot\left(I_{A}^{2}+I_{B}^{2}+I_{C}^{2}\right)},
$$

is an indication of the portion of the source apparent power that is directly caused by the source neutral-point displacement with respect to an ideal voltage reference point.

The foregoing expressions of the neutral-displacement power and its components are formally similar, as enunciated above, to Equations (9)-(11) of the neutral-displacement instantaneous power and its components. The proposed neutral-displacement power $\left(S_{n}\right)$ and its components have the same dimensions as the apparent power, and their unit is volt-ampere (VA).

\subsubsection{Expressions of the Neutral-Displacement Powers Using Ideal Voltage Reference Points}

An example of an ideal voltage reference point is the neutral point of a balanced star-configured load with an infinite impedance in each phase, connected to an ideal ground with zero resistance (Figure 3). The main attribute of such an ideal grounding voltage reference point $(\mathrm{G})$ is a zero-sequence line-to-ideal-reference point voltage of zero $\left(V_{A G 0}=0\right)$, according to Fortescue's theorem [31]. The apparent power measured by the power analyzer at the PCC of the system in Figure 3 when the voltage reference point is an ideal grounded point $(\mathrm{G})$ can be expressed as follows, according to Buchholz [20]:

$$
S_{p c c}^{i}=\sqrt{\left(V_{A G}^{2}+V_{B G}^{2}+V_{C G}^{2}\right) \cdot\left(I_{A}^{2}+I_{B}^{2}+I_{C}^{2}\right)},
$$


where the superscript $i$ indicates that the apparent power is obtained using an ideal grounding point as the voltage reference point. The quadratic difference between the load apparent power $\left(S_{l}\right)$ measured using the neutral point $(n)$ as the voltage reference point and the apparent power measured at the PCC $\left(S_{p c c}^{i}\right)$ can be determined as follows:

$$
\begin{gathered}
S_{l}^{2}-\left(S_{p c c}^{i}\right)^{2}=\left[\left(V_{A n}^{2}+V_{B n}^{2}+V_{C n}^{2}\right)-\left(V_{A G}^{2}+V_{B G}^{2}+V_{C G}^{2}\right)\right] \cdot\left(I_{A}^{2}+I_{B}^{2}+I_{C}^{2}\right)= \\
=3 \cdot\left(V_{A n 0}^{2}-V_{A G 0}^{2}\right) \cdot\left(I_{A}^{2}+I_{B}^{2}+I_{C}^{2}\right) .
\end{gathered}
$$

Because a line-to-ideal grounding point voltage does not have zero-sequence components $\left(V_{A G 0}=0\right)$, according to Fortescue's theorem, it is obtained using Equation (30).

$$
\sqrt{S_{l}^{2}-\left(S_{p c c}^{i}\right)^{2}}=\sqrt{3 \cdot V_{A n 0}^{2} \cdot\left(I_{A}^{2}+I_{B}^{2}+I_{C}^{2}\right)}=S_{n l}
$$

Hence, the load apparent power difference in the system in Figure 3 measured by the power analyzer using either the load neutral point $(n)$ or an ideal grounding point $(G)$ as the voltage reference point can be determined from the load component of the neutral-displacement power $\left(S_{n l}\right)$. Proceeding in the same way,

$$
\sqrt{S_{s}^{2}-\left(S_{p c c}^{i}\right)^{2}}=\sqrt{3 \cdot V_{A N O}^{2} \cdot\left(I_{A}^{2}+I_{B}^{2}+I_{C}^{2}\right)}=S_{n s}
$$

the apparent power difference measured by the power analyzer at the source of the system in Figure 3 when the voltage reference point is either the source neutral point $(N)$ or an ideal grounding point $(G)$, and it is determined by the source component of the neutral-displacement power $\left(S_{n s}\right)$.

As it was observed in Section 3.1., a comparison of Equations (14) and (31) revealed some formal similarities.

(1) Both equations contain the same quantities (voltages, currents, and powers).

(2) The quantities are instantaneous (Equation (14)), and they are the square of the RMS voltages and currents or square of the powers (Equation (31)).

These similarities also apply to Equations (16) and (32). In our opinion, they suggest that the neutral-displacement powers $\left(S_{n l}\right.$ and $S_{n s}$ ) given by Equations (31) and (32) quantify the effects of the neutral displacement phenomenon identified by the instantaneous powers in Equations (14) and (16).

\subsubsection{Expressions of the Neutral-Displacement Powers Using a Real Voltage Reference Point}

A real voltage reference point $\left(G^{\prime}\right)$ may be the neutral point of three star-connected quasi-balanced large but not infinite impedances, or a grounding point with a non-zero voltage. The grounding points in power systems are usually real.

A zero-sequence line-to-real grounding point voltage $\left(V_{A G^{\prime} 0}\right)$ generally has a small but not zero value.

If the voltage reference point $\left(G^{\prime}\right)$ is a real grounding point, the apparent power measured by the power analyzer at the PCC of the system in Figure 3 can be expressed as follows, according to Buchholz [20]:

$$
S_{p c c}^{r}=\sqrt{\left(V_{A G^{\prime}}^{2}+V_{B G^{\prime}}^{2}+V_{C G^{\prime}}^{2}\right) \cdot\left(I_{A}^{2}+I_{B}^{2}+I_{C}^{2}\right)}
$$

where the superscript $r$ indicates that the apparent power is determined using a real grounding point as the voltage reference point. If the voltage reference is either a real grounding point $\left(G^{\prime}\right)$ or an ideal grounding point $(G)$, the quadratic difference between the apparent powers measured by the power analyzer at the PCC of the system in Figure 3 would satisfy the following, based on Equations (30) and (34):

$$
\left(S_{p c c}^{r}\right)^{2}-\left(S_{p c c}^{i}\right)^{2}=3 \cdot\left(V_{A G^{\prime} 0}^{2}-V_{A G 0}^{2}\right) \cdot\left(I_{A}^{2}+I_{B}^{2}+I_{C}^{2}\right)
$$


Because the zero-sequence line-to-ideal grounding point voltage is zero $\left(V_{A G 0}=0\right)$, whereas the zero-sequence line-to-real grounding point is non-zero $\left(V_{A G^{\prime} 0} \neq 0\right)$, we have

$$
\left(S_{p c c}^{r}\right)^{2}-\left(S_{p c c}^{i}\right)^{2}=3 \cdot V_{A G^{\prime} 0}^{2} \cdot\left(I_{A}^{2}+I_{B}^{2}+I_{C}^{2}\right)=S_{n, p c c}^{2} .
$$

The parameter $S_{n, p c c}$ is the neutral-displacement power measured at the PCC using a real grounding point $\left(G^{\prime}\right)$.

From Equations (19) and (33), the quadratic difference between the load apparent powers of the system in Figure 3 measured by the power analyzer using the load neutral point $(n)$ and the real grounding point $\left(G^{\prime}\right)$ as the voltage reference points, respectively, satisfies

$$
S_{l}^{2}-\left(S_{p c c}^{r}\right)^{2}=3 \cdot\left(V_{A n 0}^{2}-V_{A G^{\prime} 0}^{2}\right) \cdot\left(I_{A}^{2}+I_{B}^{2}+I_{C}^{2}\right)=S_{n l}^{2}-S_{n, p c c}^{2} .
$$

The load apparent power $\left(S_{l}\right)$ can thus be obtained in terms of the PCC apparent power $\left(S_{p c c}^{r}\right)$, the load neutral-displacement power $\left(S_{n l}\right)$, and the PCC neutral-displacement power $\left(S_{n, p c c}\right)$, as follows:

$$
S_{l}=\sqrt{\left(S_{p c c}^{r}\right)^{2}+S_{n l}^{2}-S_{n, p c c}^{2}}
$$

In the same way, the quadratic difference between the apparent powers of the source of the system in Figure 3 measured by the power analyzer using the source neutral point $(N)$ and a real grounding point $\left(G^{\prime}\right)$, respectively, can be obtained from Equations (19) and (33) as follows:

$$
S_{s}^{2}-\left(S_{p c c}^{r}\right)^{2}=3 \cdot\left(V_{A N 0}^{2}-V_{A G^{\prime} 0}^{2}\right) \cdot\left(I_{A}^{2}+I_{B}^{2}+I_{C}^{2}\right)=S_{n s}^{2}-S_{n, p c c}^{2} .
$$

Hence, the source apparent power $\left(S_{S}\right)$ can be expressed as a function of the PCC apparent power $\left(S_{p c c}^{r}\right)$ as follows:

$$
S_{s}=\sqrt{\left(S_{p c c}^{r}\right)^{2}+S_{n s}^{2}-S_{n, p c c}^{2}}
$$

where $S_{n s}$ is the source neutral-displacement power, and $S_{n, p c c}$ is the neutral-displacement power measured at the PCC.

\section{Practical Experiments}

The apparent power measurements of a commercial power analyzer (Fluke 437 Series II) and our prototype power analyzer referred to as SIMPELEC [30] were tested in a laboratory and on real-world electrical networks using the expressions of the apparent and neutral-displacement powers in Section 3. The Fluke 437 power analyzer measures the apparent powers using the Buchholz formulation, while our SIMPELEC analyzer measures the same apparent powers, as well as the neutral-displacement powers in Section 3.

The laboratory measurements were performed on a Chroma programmable three-phase source model 61,700 [32] under three different conditions: (1) sinusoidal balanced voltages, (2) sinusoidal unbalanced voltages, and (3) non-sinusoidal balanced voltages. The real-world network measurements were performed on the electrical network of a utility service using only the SIMPELEC analyzer, which is described in the Spanish Granted Patent [30], whose main features are described below.

The hardware constitutes the following:

- Processor board: PCM-9581 On-board Intel Pentium (Advantech) [33].

- Data acquisition: PCI-6220 of National Instruments, 16 bits, 16 AI, 250 kS/s [34].

- Transducers: Voltage Hall Effect LV 25-P (LEM) with accuracy 0.9\% [35], AC Current Clamps Fluke i5sPQ3, 5 A, accuracy $1 \%$ [36]. 
The firmware of the SIMPELEC analyzer is based on LabVIEW platform to measure the complex RMS values (module and angle) of the voltages and currents, according to the following steps:

Step 1. Measurement of the line-to-neutral voltages and the line and neutral currents, using Hall sensors.

Step 2. Acquisition of samples of the line-to-neutral voltages and line and neutral currents from the previous measurements, using a 40.96-kS/s-per-channel acquisition card.

Step 3. Calculation of the complex RMS (CRMS) values (module and angle) applying fast Fourier transform (FFT) to the above samples.

Step 4. Calculation of apparent powers.

It is noted in Table 1 that the difference between the apparent powers measured by the Fluke 437 and SIMPELEC analyzers is due to the accuracy of the voltage transducers used by these analyzers. As it may be observed in Table 1, Fluke analyzer is an A-Class instrument and, therefore, more accurate than the SIMPELEC. However, if we analyze the apparent powers measured in the following examples, the maximum difference between these powers measured by both analyzers is less than $0.15 \%$. Thus, this accuracy may be negligible in determining the neutral-displacement powers, which are much smaller than the apparent powers.

Table 1. Comparison of the transducer features used by the Fluke 437 series II and SIMPELEC analyzers.

\begin{tabular}{ccc}
\hline Analyzer & $\begin{array}{c}\text { Voltage } \\
\text { Accuracy \% }\end{array}$ & $\begin{array}{c}\text { Current Clamp } \\
\text { Accuracy \% }\end{array}$ \\
\hline Fluke 437-II & \pm 0.1 & 1 \\
SIMPELEC & \pm 0.9 & 1 \\
\hline
\end{tabular}

\subsection{Laboratory Applications with Three-Phase Voltage Source}

Figure 4 is a photo of the three-phase circuit used for the laboratory applications. The three-phase voltage source (1) supplied an unbalanced load (5) consisting of De Lorenzo resistances [37] with practical equivalent phase resistances of $R_{a}=241.58 \Omega, R_{b}=419.31 \Omega$, and $R_{c}=840.62 \Omega$. To achieve significant differences between the source and load apparent powers, a neutral path was formed by a resistance $r_{n}=185.33 \Omega(4)$. The Fluke 437 (2) and SIMPELEC (3) analyzers were series-connected between the source and the load.

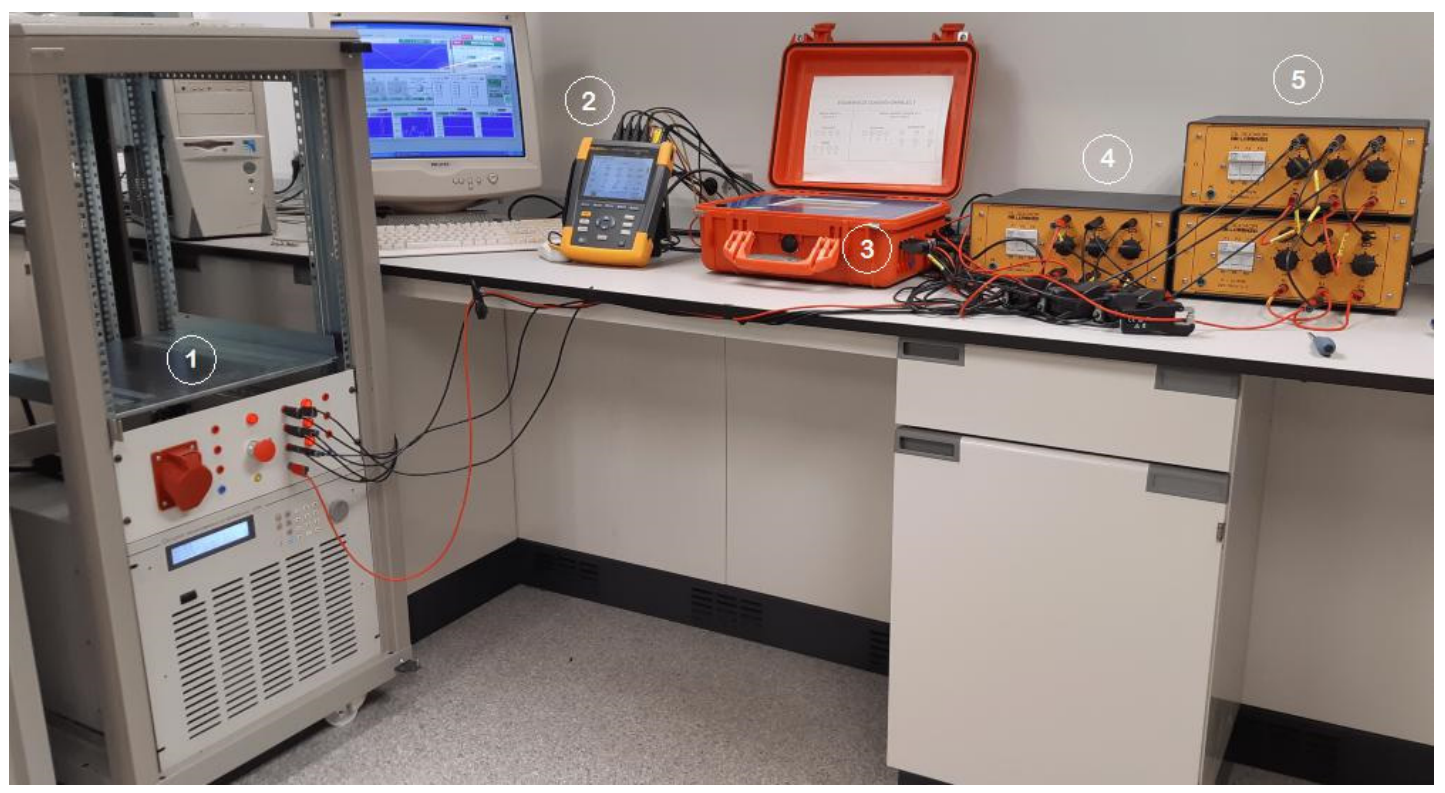

Figure 4. Montage of the testing circuit: (1) Chroma source; (2) Fluke 437; (3) SIMPELEC analyzer; (4) neutral resistances and ammeter clamps; (5) load resistances. 


\subsubsection{Sinusoidal and Balanced Voltage Source}

In this practical application, the source was adjusted to supply sinusoidal and balanced voltages with an RMS phase-to-neutral value of $230 \mathrm{~V}$. The voltages and currents measured by the Fluke 437 and SIMPELEC power analyzers for the circuit in Figure 4 are presented in Figures 5-7 using either the source neutral point $(\mathrm{N})$ or the load neutral point $(\mathrm{n})$ as voltage reference points.

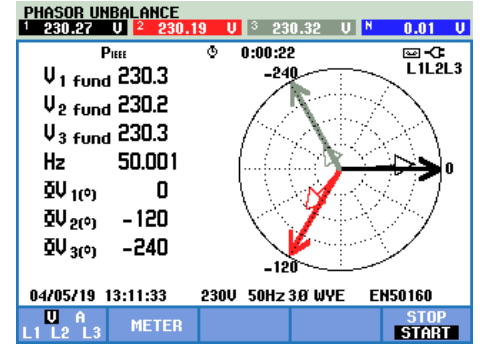

(a)

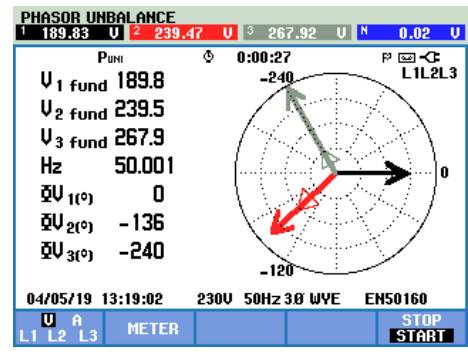

(b)

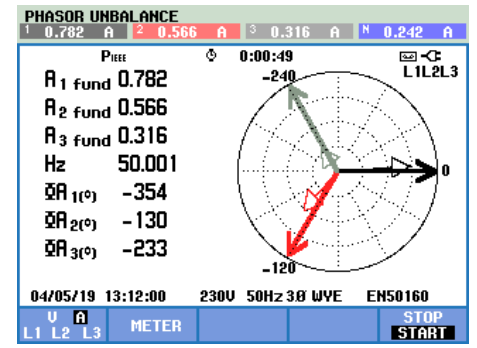

(c)

Figure 5. Screenshots of the Fluke 437 power analyzer for a sinusoidal and balanced source: (a) source voltage; (b) load voltage; (c) line current.

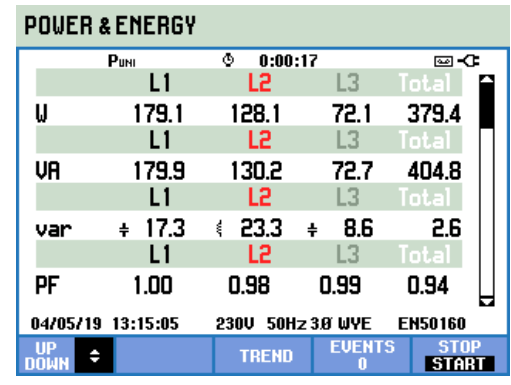

(a)

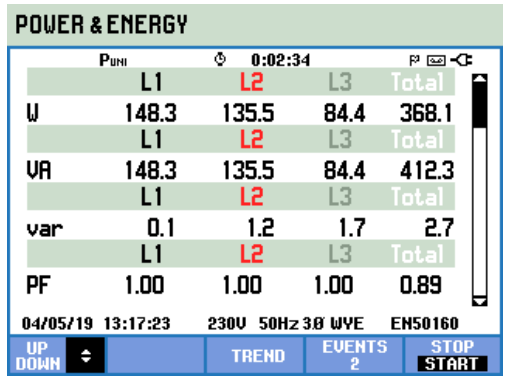

(b)

Figure 6. Buchholz's power screenshots of the Fluke 437 under balanced voltage supply using as voltage reference the neutral point of the (a) source, and (b) load.

\begin{tabular}{|c|c|c|c|}
\hline \multicolumn{4}{|c|}{ POWERS } \\
\hline Active Positive ( $\mathrm{P}^{+}$ & & Active $(P)$ & \\
\hline 379.7596 & w & 379,7604 & w \\
\hline Reactive Positive & $Q+)$ & Distortion $\left(\mathrm{SH}_{\mathrm{H}}\right)$ & \\
\hline 0,0302 & VAr & 0,2489 & VA \\
\hline Unbalence (Su) & & Neutral $\left(S_{N}\right)$ & \\
\hline 141,1021 & VA & 0,0666 & VA \\
\hline Apparent (S) & & Power Factor ( $\lambda$ & \\
\hline 405,1262 & VA & 0,94 & \\
\hline
\end{tabular}

(a)

\begin{tabular}{|c|c|c|c|}
\hline \multicolumn{4}{|c|}{ POWERS } \\
\hline Active Positive (P+ & & Active $(P)$ & \\
\hline 379.8450 & w & 368,6740 & w \\
\hline Reactive Positive & $Q+)$ & Distortion (SH) & \\
\hline 0.0229 & VAr & 0.2539 & VA \\
\hline Unbalence (Su) & & Neutral (SN) & \\
\hline 161,6903 & VA & 78,8976 & VA \\
\hline Apparent (S) & & Power Factor $(\lambda)$ & \\
\hline 412.8269 & VA & 0,89 & CAP \\
\hline
\end{tabular}

(b)

Figure 7. Screenshots of SIMPELEC power analyzer during measurement of apparent and neutral-displacement powers using as the voltage reference the neutral point of the (a) source, and (b) load.

Table 2 summarizes the line-to-neutral voltages and line currents measured by the Fluke 437 power analyzer (Figure 5), as well as the source and load zero-sequence voltages and neutral current measured by the SIMPELEC power analyzer. Figure 7a,b show the apparent and neutral-displacement powers registered by the SIMPELEC power analyzer, according to Buchholz's formulation. 
Table 2. Voltages and currents measured by the Fluke 437 and SIMPELEC $\left({ }^{*}\right)$ power analyzers for the source and load of the tested circuit under sinusoidal and balanced voltage supply $\left(V_{0}=\right.$ zero-sequence voltage, $I_{N}=$ neutral current).

\begin{tabular}{ccccccc}
\hline & \multicolumn{3}{c}{ Voltages (V) } & \multicolumn{2}{c}{ Currents (A) } \\
\cline { 2 - 6 } & \multicolumn{2}{c}{ Source } & \multicolumn{2}{c}{ Load } & \multicolumn{2}{c}{} \\
\cline { 2 - 6 } & RMS (V) & Angle $\left(^{\circ}\right)$ & RMS (V) & Angle $\left(^{\circ}\right)$ & RMS (A) & Angle $\left(^{\circ}\right)$ \\
\hline A-phase & 230.27 & 0 & 189.83 & 5.5 & 0.782 & 5.5 \\
\hline B-phase & 230.19 & -120 & 239.47 & -130.5 & 0.566 & -130.5 \\
\hline C-phase & 230.32 & -240 & 267.92 & 125.5 & 0.316 & 125.5 \\
\hline$V_{0} / I_{N}$ & $0.04^{*}$ & $82.41^{*}$ & $44.84^{*}$ & $156.36^{*}$ & $0.242 / 0.246^{*}$ & $-23.69^{*}$ \\
\hline
\end{tabular}

The source and load apparent powers in the third column of Table 3 were measured by the Fluke 437 and SIMPELEC power analyzers using the neutral point $(\mathrm{N}$ or $\mathrm{n})$ of the corresponding subsystem (source or load) as the voltage reference point. The source and load neutral-displacement powers in the fourth column of Table 3 were measured by the SIMPELEC power analyzer (Figure 7a,b). The fifth column of Table 3 gives the source and load apparent powers determined using the neutral point of the opposite subsystem as the voltage reference point. As an example of how the values of the fifth column were calculated, we wanted to determine Buchholz's source apparent power, but the source neutral point $(\mathrm{N})$ was not accessible and, thus, we used the load neutral point (n) as the voltage reference. The apparent power measured by the Fluke 437 power analyzer using $n$ as the voltage reference point was the load apparent power (412.3 VA, third column in Table 3), while the measured load neutral-displacement power was 78.8879 VA (fourth column in Table 3). Thus, if the source neutral-displacement power was known (0.0666 VA, Table 2), the source apparent power according to Buchholz could be determined from Equations (25) and (26) as follows:

$$
S_{s}=\sqrt{S_{l}^{2}-S_{n l}^{2}+S_{n s}^{2}}=\sqrt{(412.3)^{2}-(78.8976)^{2}+(0.0686)^{2}}=404.68 \mathrm{VA}
$$

Table 3. Apparent and neutral-displacement powers measured by the Fluke 437 and SIMPELEC analyzers for the test circuit. $\left(^{*}\right)$ Calculated using the neutral point of the opposite subsystem as voltage reference point.

\begin{tabular}{ccccc}
\hline Reference Point & Analyzer & Apparent (VA) & Neutral (VA) & Apparent * (VA) \\
\hline \multirow{2}{*}{$N$} & Fluke 437 & 404.8 & 0.0666 & 404.68 \\
\cline { 2 - 5 } & SIMPELEC & 405.126 & 0.0666 & 405.22 \\
\hline \multirow{2}{*}{$n$} & Fluke 437 & 412.3 & 78.8976 & 412.41 \\
\cline { 2 - 5 } & SIMPELEC & 412.827 & 78.8976 & 412.73 \\
\hline
\end{tabular}

This result is only slightly less than $404.8 \mathrm{VA}$, which was the real value obtained using the source neutral point $(\mathrm{N})$ as the voltage reference point. A comparison of the real values of the source and load apparent powers measured by the SIMPELEC power analyzer (third column in Table 3) with the values calculated using Equations (25) and (26) reveals that they are very close. This verifies the validity of Equations (25) and (26). However, because the sources are generally quasi-balanced and hardly distorted, their neutral-displacement powers are usually less than the load neutral-displacement powers (Table 3). The source apparent powers can, thus, be estimated with great precision exclusively from the measured load apparent and neutral-displacement powers. This was also confirmed by the experimental results for the real-world electrical network (Section 4.2) The procedure has significant potential in practical applications since it reduces the number of power analyzers required to measure the apparent powers in different parts of a power system. 


\subsubsection{Sinusoidal and Unbalanced Voltage Source}

In this practical application, the source was adjusted to supply sinusoidal and unbalanced voltages with a zero-sequence component of $38.66 \mathrm{~V}$ (Table 4). The load and neutral path resistances were maintained at the same values as in the previous laboratory application. The source conditions included displacement of the source and load neutral points with respect to the real grounding point of the installation.

Table 4. Voltages and currents measured by the Fluke 437 and SIMPELEC power analyzers for different voltage reference points ( $V_{0}=$ zero-sequence voltage, $I_{N}=$ neutral current). PCC—point of common coupling.

\begin{tabular}{ccccccccc}
\hline & \multicolumn{2}{c}{ Source Voltage } & \multicolumn{2}{c}{ Load Voltage } & \multicolumn{2}{c}{ PCC Voltage } & \multicolumn{2}{c}{ Line Current } \\
\cline { 2 - 9 } & RMS (V) & Angle $\left({ }^{\circ}\right)$ & RMS (V) & Angle $\left(^{\circ}\right)$ & RMS (V) & Angle $\left({ }^{\circ}\right)$ & RMS (A) & Angle $\left({ }^{\circ}\right)$ \\
\hline A-phase & 240.2 & 0 & 182.18 & 6.19 & 201.38 & -0.05 & 0.748 & 6.19 \\
\hline B-phase & 225.17 & -106 & 230.62 & -121.53 & 238.97 & -114.97 & 0.545 & -121.53 \\
\hline C-phase & 225.3 & -254 & 265.09 & 117.07 & 238.76 & 115 & 0.312 & 117.07 \\
\hline$V_{\mathbf{0}} / \mathbf{I}_{\boldsymbol{N}}$ & 38.67 & 0.02 & 28.12 & 135.46 & 0.2 & -136.52 & 0.334 & -18.56 \\
\hline
\end{tabular}

Table 4 summarizes the values of the voltages and currents measured by the Fluke 437 and SIMPELEC power analyzers, which are represented in Figures 8 and $9 \mathrm{a}$ for different voltage reference points, namely, the source $(\mathrm{N})$, load $(\mathrm{n})$, and real grounding point $\left(\mathrm{G}^{\prime}\right)$.

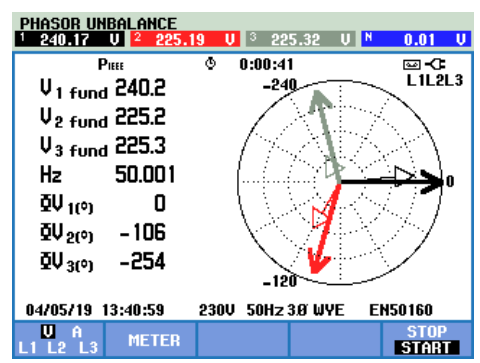

(a)

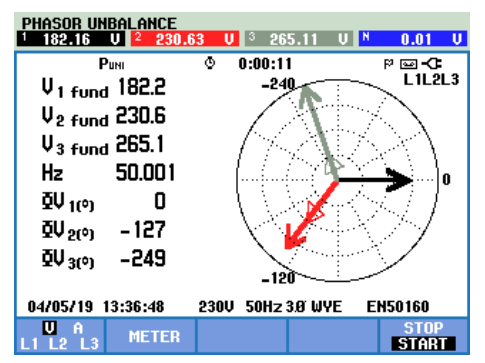

(b)

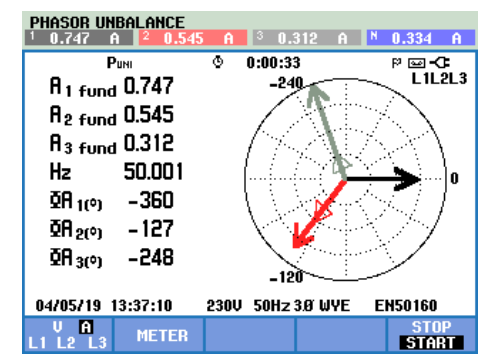

(c)

Figure 8. Screenshots of the Fluke 437 power analyzer for sinusoidal and unbalanced source voltages: (a) source voltage; (b) load voltage; (c) line current.

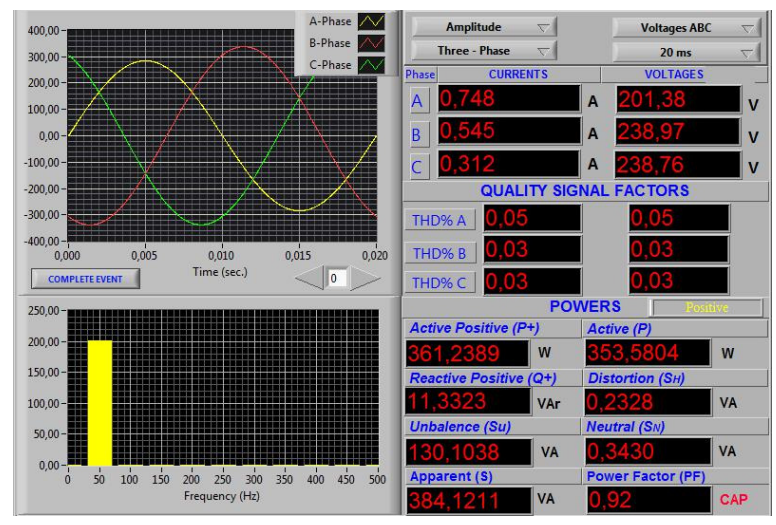

Figure 9. Main screen of the SIMPELEC power analyzer using a real grounding point $(G)$ as the voltage reference point. 
The apparent powers measured by the SIMPELEC (Figure 9) and Fluke 437 (Figure 10) power analyzers are presented in the third column of Table 5 . The neutral-displacement powers were measured by the SIMPELEC power analyzer according to Equations (27), (28), and (35).

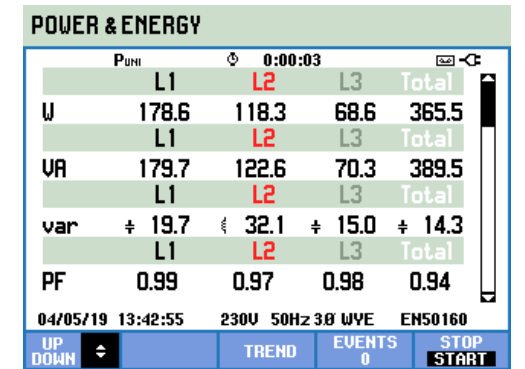

(a)

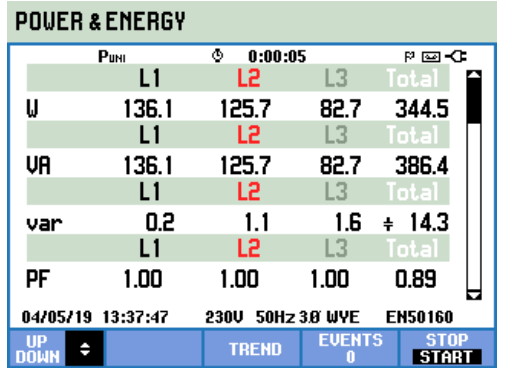

(b)

Figure 10. Buchholz's power screenshots of the Fluke 437 under unbalanced voltage supply using as voltage reference the neutral point of the (a) source, and (b) load.

Table 5. Apparent and neutral-displacement powers measured by the Fluke 437 and SIMPELEC power analyzers for the PCC of the tested circuit with respect to the voltage reference point $(N, n$, or $G)$ ). $\left.{ }^{*}\right)$ Calculated from the powers measured at source and load using the grounding point $(\mathrm{G})$ as voltage reference point (ref. pt.).

\begin{tabular}{ccccc}
\hline Reference Point & Analyzer & $\begin{array}{c}\text { Apparent } \\
\text { (VA) }\end{array}$ & $\begin{array}{c}\text { Neutral }\left(S_{n}\right) \\
\text { (VA) }\end{array}$ & $\begin{array}{c}\text { Apparent * } \\
\text { (VA) }\end{array}$ \\
\hline $\begin{array}{c}\text { Source } \\
\text { (ref. pt. } \boldsymbol{N} \text { ) }\end{array}$ & Fluke 437 & 389.5 & 65.406 & 389.2 \\
\hline SIMPELEC & 389.65 & 65.406 & 389.648 \\
\hline Load & Fluke 437 & 386.4 & 47.562 & 386.49 \\
(ref. pt. $\boldsymbol{n}$ ) & SIMPELEC & 386.57 & 47.562 & 387.05 \\
\hline PCC & Fluke 437 & 383.6 & 0.343 & - \\
(ref. pt. $\boldsymbol{G}$ ) & SIMPELEC & 384.12 & 0.343 & - \\
\hline
\end{tabular}

If the source and load neutral points ( $N$ and $n$ ) are not available for use as voltage reference points, instrument manufacturers recommend the use of a grounding point $(G)$ near the PCC. However, this is only an approximate solution because the apparent power measured by a power analyzer at the PCC using a grounding point as voltage reference is usually smaller than the apparent powers measured using either the source or the load neutral points ( $N$ or $n$ ) as voltage reference (third column in Table 4), especially when the source and load are unbalanced and/or distorted. Nevertheless, source and load apparent powers ( $S_{s}^{*}$ and $S_{l}^{*}$ ) could be determined (fifth column in Table 5) very close to the real values (third column in Table 5) from the apparent powers measured at PCC using the grounding point $(G)$ as the voltage reference and the values of the neutral-displacement powers $\left(S_{n s}\right.$ and $\left.S_{n l}\right)$ indicated in fourth column in Table 5, applying Equations (37) and (39).

$$
S_{l}^{*}=\sqrt{\left(S_{p c c}^{r}\right)^{2}+S_{n l}^{2}-S_{n, p c c}^{2}} \text { and } S_{s}^{*}=\sqrt{\left(S_{p c c}^{r}\right)^{2}+S_{n s}^{2}-S_{n, p c c}^{2}}
$$

Indeed, as an example that illustrates how the values of apparent powers of the source and load could approximately be obtained from the powers measured using the grounding point $(G)$ as the voltage reference point (fifth column in Table 5), the apparent power of the source $\left(S_{s}^{*}\right)$ in the test circuit of Figure 4 would have the following value, using the second above equation in which $S_{p c c}^{r}=384.12 \mathrm{VA}$ is the apparent power measured by the SIMPELEC analyzer at the PCC (third column, last file in Table 5) and the neutral-displacement powers of the source $\left(S_{n s}=65.406 \mathrm{VA}\right)$ and PCC $\left(S_{n, p c c}=0.343 \mathrm{VA}\right)$ are obtained from the fourth column in Table 5: 


$$
S_{s}^{*}=\sqrt{\left(S_{p c c}^{r}\right)^{2}+S_{n s}^{2}-S_{n, p c c}^{2}}=\sqrt{384.12^{2}+65.406^{2}-0.343^{2}}=389.648 \mathrm{VA} .
$$

This result would agree well with the real value of the apparent power measured by the SIMPELEC power analyzer using the source neutral point $(\mathrm{N})$ as the reference point $(389.65 \mathrm{VA})$.

\subsubsection{Distorted Voltage Source}

In this practical application, the three-phase source was programmed to supply balanced and distorted line-to-neutral voltages formed by a $230-\mathrm{V} 50-\mathrm{Hz}$ fundamental-frequency harmonic and a $23-\mathrm{V} 150-\mathrm{Hz}$ third harmonic. The registrations of the Fluke 437 and SIMPELEC power analyzers are shown in Figures 11 and 12. The load and neutral path resistances were maintained at the same values as in the previous tests. The RMS results for the different parts of the circuit are presented in Table 6 .

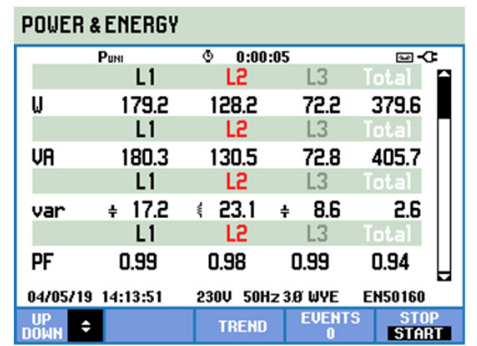

(a)

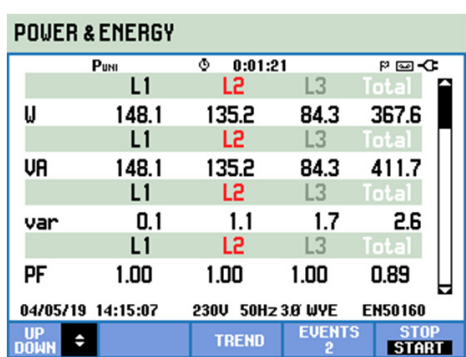

(b)

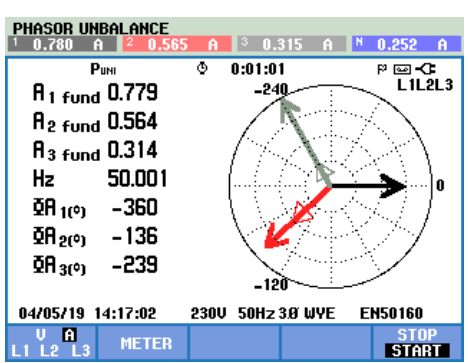

(c)

Figure 11. Screenshots of Fluke 437 power analyzer showing the currents and Buchholz's powers measured under supply of distorted voltage: (a) source power, (b) load power, and (c) line and neutral currents.

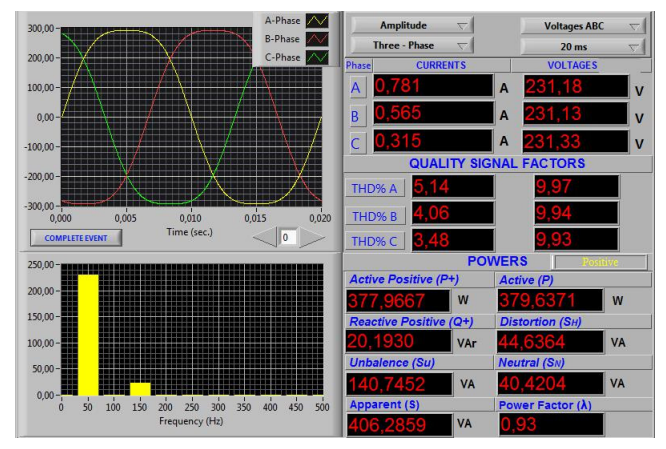

(a)

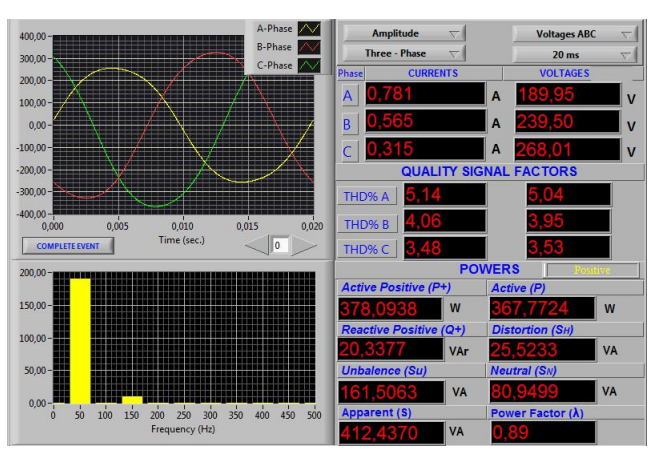

(b)

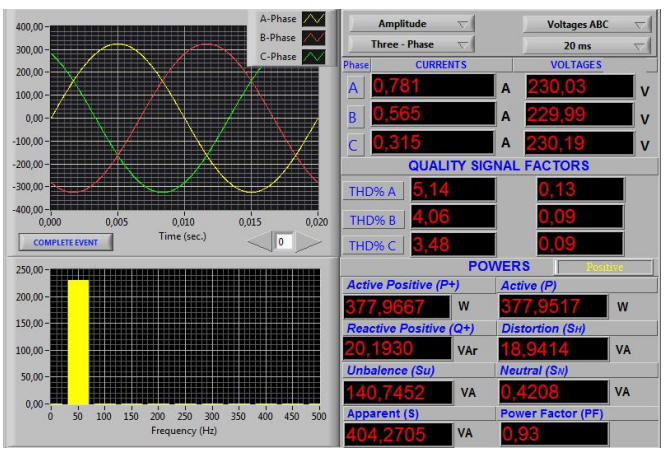

(c)

Figure 12. Main screens of the SIMPELEC analyzer when the source is distorted and with representation of the line-to-neutral voltage waves, using the voltage reference point as (a) the neutral point of source $(\mathrm{N}),(\mathbf{b})$ the neutral point of load $(\mathrm{n})$, and (c) a real grounding point $(\mathrm{G})$. 
Table 6. Harmonic voltages and currents measured by the SIMPELEC power analyzer using different voltage reference points $\left(V_{0}=\right.$ zero-sequence voltage, $I_{N}=$ neutral current).

\begin{tabular}{ccccccccc}
\hline & \multicolumn{2}{c}{ Source Voltage } & \multicolumn{2}{c}{ Load Voltage } & Real Grounding Point Voltage & \multicolumn{2}{c}{ Line Current } \\
\cline { 2 - 10 } & $\mathbf{5 0 ~ H z}$ & $\mathbf{1 5 0} \mathbf{~ H z}$ & $\mathbf{5 0 ~} \mathbf{~ H z}$ & $\mathbf{1 5 0 ~} \mathbf{~ z}$ & $\mathbf{5 0 ~ H z}$ & $\mathbf{1 5 0 ~} \mathbf{~ H z}$ & $\mathbf{5 0 ~ H z}$ & $\mathbf{1 5 0} \mathbf{~ H z}$ \\
\hline A-phase & 230.0 & 23.0 & 189.69 & 9.536 & 231.2 & 0.275 & 0.78 & 0.04 \\
\hline B-phase & 230.0 & 23.0 & 239.32 & 9.49 & 231.2 & 0.211 & 0.565 & 0.023 \\
\hline C-phase & 230.2 & 23.0 & 267.85 & 9.5 & 231.3 & 0.211 & 0.315 & 0.011 \\
\hline $\boldsymbol{V}_{\mathbf{0}} / \mathbf{I}_{\boldsymbol{N}}$ & 0.07 & 23.0 & 45.08 & 9.508 & 0.07 & 0.23 & 0.246 & 0.071 \\
\hline
\end{tabular}

The total RMS values of the voltages and currents in the tested circuit were obtained by applying Fourier series to the harmonic components presented in Table 6. Hence, using Equation (24), the RMS values of the zero-sequence line-to-neutral voltages at the source, load, and PCC for the use of a real grounding point as the voltage reference point were respectively as follows:

$$
\begin{gathered}
V_{A N 0}=\sqrt{0.07^{2}+23^{2}}=23 \mathrm{~V}, \quad V_{A n 0}=\sqrt{45.08^{2}+9.508^{2}}=46.07 \mathrm{~V}, \\
V_{A G 0}=\sqrt{0.07^{2}+0.23^{2}}=0.24 \mathrm{~V} .
\end{gathered}
$$

The apparent powers measured by the analyzers are presented in the third column of Table 7. The neutral-displacement powers in the fourth column of Table 7 were measured at the PCC by the SIMPELEC power analyzer using the neutral points of source $(\mathrm{N})$ and load $(\mathrm{n})$, as well as with a real grounding point $(\mathrm{G})$, as the voltage reference points, respectively, according to Equations (27), (28), and (35).

Table 7. Apparent powers measured by the Fluke 437 and SIMPELEC power analyzers for the PCC of the tested circuit with respect to the selected voltage reference point $(\mathrm{N}, \mathrm{n}$, or $\left.\mathrm{G}) .{ }^{*}\right)$ Calculated in source and load from the apparent powers measured at PCC using the grounding point $(\mathrm{G})$ as voltage reference point.

\begin{tabular}{ccccc}
\hline Reference Point & Analyzer & $\begin{array}{c}\text { Apparent } \\
\text { (VA) }\end{array}$ & $\begin{array}{c}\text { Neutral }\left(S_{n}\right) \\
\text { (VA) }\end{array}$ & $\begin{array}{c}\text { Apparent * } \\
\text { (VA) }\end{array}$ \\
\hline $\begin{array}{c}\text { Source } \\
\text { (ref. pt. } \boldsymbol{N} \text { ) }\end{array}$ & Fluke 437 & 405.7 & 40.42 & 405.8 \\
\hline Load & SIMPELEC & 406.28 & 40.42 & 406.27 \\
(ref. pt. $\boldsymbol{n}$ ) & Fluke 437 & 411.7 & 80.95 & 411.83 \\
PCC & FlMPELEC & 412.43 & 80.95 & 412.29 \\
\hline (ref. pt. $\boldsymbol{G}$ ) & SIMke 437 & 403.8 & 0.42 & - \\
\hline
\end{tabular}

The source and load apparent powers indicated in the fifth column of Table 7 were obtained from the apparent powers measured at the PCC using a real grounding point $(G)$ and Equations (37) and (39). Hence, for example, to calculate the load apparent power ( $\left.S_{l}^{*}\right)$ from PCC apparent power $\left(S_{p c c}^{r}=403.8 \mathrm{VA}\right.$, Table 7 , measured by the Fluke 437 power analyzer), the load and PCC neutral-displacement powers $\left(S_{n l}=80.95 \mathrm{VA}, S_{n, p c c}=0.42 \mathrm{VA}\right)$ in Equation (37) should be used.

$$
S_{l}^{*}=\sqrt{\left(S_{p c c}^{r}\right)^{2}+S_{n l}^{2}-S_{n, p c c}^{2}}=\sqrt{403.8^{2}+80.95^{2}-0.42^{2}}=411.83 \mathrm{VA} .
$$

This result is very close to the real value of 411.7 VA (third column of Table 7), measured by the Fluke 437 power analyzer using the neutral point of the load as voltage reference. The general results obtained for the tested circuit when it was supplied with the distorted voltage (Table 7) are comparable with those obtained when the circuit was supplied by an unbalanced voltage (Table 5). 


\subsection{Real-World Electrical Network}

This experiment aimed to also verify Equations (25) and (26) in real-world installations, and not only in controlled conditions at the laboratory. Additionally, the experiment was used to prove that measuring only the load powers is enough to determine the apparent powers of the source (the transformer, in this case) with very good approximation.

An electrical network of the utility Eléctrica de Vinalesa SCV, Valencia, Spain, was used for this practical experience. The waves of the line currents and source voltages, as well as the source and load powers registered by the SIMPELEC power analyzer, are shown in Figure 13a,b. The network power was supplied by a 400-kVA 20-kV/400-V Dyn11 three-phase transformer through a three-phase four-wire balanced buried line of cross-section $25 \mathrm{~mm}^{2}$ and length $28 \mathrm{~m}$ (from the transformer to the load distribution panel). The power consumptions of each phase of the load are shown in Figure 14. The line currents were distorted and strongly unbalanced (Figure 13b), while the voltages were hardly distorted (Figure 13a).

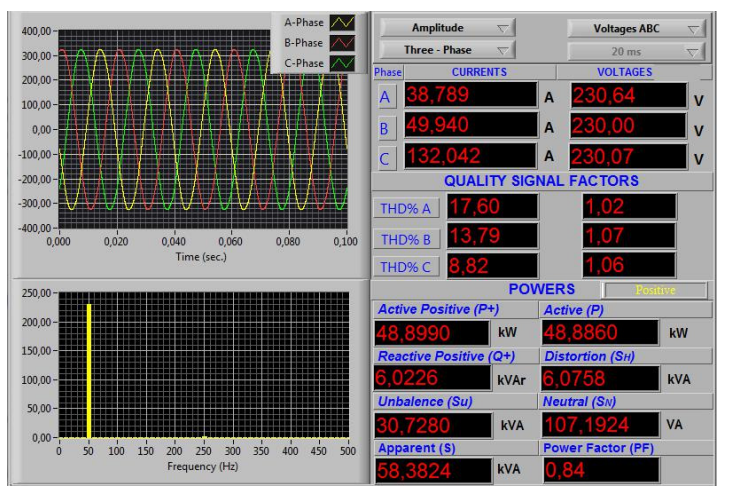

(a)

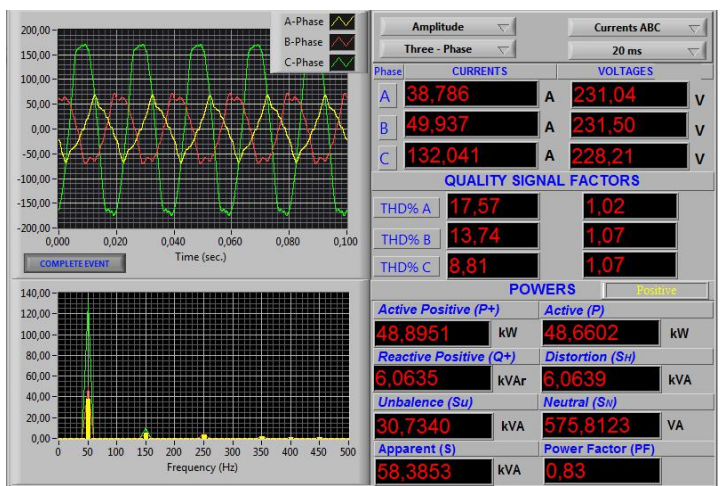

(b)

Figure 13. Main screens of the SIMPELEC power analyzer for measurement of the (a) source (with representation of line-to-neutral voltages), and (b) load (with representation of line currents) of the real-world electrical network.

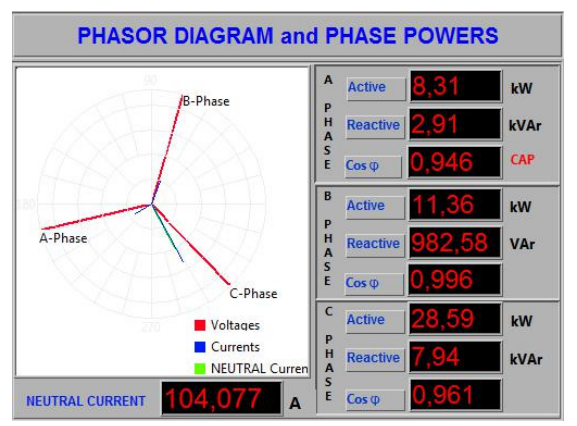

Figure 14. Screenshots of the active and reactive power consumptions in each phase of the load of the real-world electrical network measured by the SIMPELEC power analyzer.

It should be noted that, as shown in Table 8, the apparent powers measured at the PCC when the neutral point of the load (n) was used as the voltage reference point $(58,385.30 \mathrm{VA})$ were slightly higher than the apparent powers measured at the PCC using the source neutral point $(\mathrm{N})$ as the voltage reference point $(58,382.40 \mathrm{VA})$. The differences between the measured apparent powers were due to the neutral-point displacement of the load and source, caused by the non-negligible neutral conductor impedance. 
Table 8. Apparent and neutral-displacement powers measured by the SIMPELEC power analyzer for the PCC of the real-world installation with respect to the selected voltage reference point ( $\mathrm{N}$ or $\mathrm{n}$ ).

\begin{tabular}{ccc}
\hline Reference Point & $\begin{array}{c}\text { Apparent } \\
\text { (VA) }\end{array}$ & $\begin{array}{c}\text { Neutral }\left(S_{n}\right) \\
\text { (VA) }\end{array}$ \\
\hline $\begin{array}{c}\text { Source } \\
\text { (ref. pt. } N \text { ) } \\
\text { Load } \\
\text { (ref. pt. } \boldsymbol{n} \text { ) }\end{array}$ & $58,382.40$ & 107.19 \\
\hline
\end{tabular}

The source and load voltages show the effects of the neutral displacement phenomenon. While the source voltages stayed quasi-balanced, with values around $230 \mathrm{~V}$ (Figure 13a), the load voltages became unbalanced, with over-voltages greater than $231 \mathrm{~V}$ in phases $\mathrm{A}$ and $\mathrm{B}$, and sub-voltages $(228.21 \mathrm{~V})$ in phase $C$. The power effects caused by the non-negligible neutral conductor impedance were determined by the neutral-displacement powers, which were 575.81 VA for the load and only 107.19 VA for the source (Table 8).

We knew the values of the apparent and neutral-displacement powers in the source and load (represented in Table 8), because we measured these powers in both subsystems (source and load) of the real-world installation. However, usually, the powers are measured at only one part (source or load) of the power systems, making it difficult to measure two sides at once. In these cases, the procedure proposed in this paper could be very useful, because it enables determining the source apparent power, with great approximation, measuring only the load powers. Indeed the neutral-displacement power of the source $\left(S_{n s}=107.19 \mathrm{VA}\right.$, Table 8$)$ was negligible in comparison to the load neutral-displacement power $\left(S_{n l}=575.81 \mathrm{VA}\right.$, Table 8$)$, which is true in most power systems, since the sources are usually more balanced and less distorted than the loads, as may be obtained from Equations (25) and (26).

$$
S_{s} \cong \sqrt{S_{l}^{2}-S_{n l}^{2}}=\sqrt{58385.3^{2}-575.81^{2}}=58,382.46 \mathrm{VA} .
$$

This result is very close to the measured value of the source apparent power $\left(S_{s}=58,382.4 \mathrm{VA}\right.$, Table 8). The findings of this example are of great practical significance, particularly for the possibility of estimating the source apparent power of a system using only the powers measured in the load of that system, because the source neutral point is inaccessible or to save measuring instrumentation on the source.

\section{Conclusions}

The phenomenon associated with the apparent power differences measured in each subsystem of a three-phase star-configured power system, depending on the point used as the voltage reference, was examined in this paper. The phenomenon was determined to be due to the power effects caused by the neutral-point displacement voltage difference between the different voltage reference points.

A proposed power that represents the effect of this phenomenon, referred to as the neutral-displacement power $\left(S_{n}\right)$, was developed, and its expressions were derived based on Buchholz's apparent power. In each subsystem (source or load) of a three-phase star-configured power system, the value of the neutral-displacement power is determined by the adopted voltage reference point. When the voltage reference point is an ideal grounding point, the neutral-displacement power is zero, and the measured apparent power has the minimum possible value, including when the subsystem is unbalanced and/or distorted. If the voltage reference point is the neutral point of an unbalanced and/or a distorted subsystem, the neutral-displacement power would be non-zero. This is because of the existence of a voltage difference between the neutral point of the subsystem and the ideal reference point, resulting in an increase in the value of the apparent power relative to the value measured using the ideal reference point. 
The apparent power measured by a power analyzer when a real grounding point is used as the voltage reference point is slightly higher than that measured using an ideal grounding point as the reference point. This is because the neutral-displacement power for a real grounding point is non-zero, although very small. The neutral points of quasi-balanced and barely distorted subsystems in a three-phase power system can be considered as real grounded points. This enables the apparent powers of the subsystems to be determined with great precision using any real grounding point as the voltage reference point. This affords a practical means of measuring the apparent powers of the subsystems when their neutral points are not easily accessible, because they are very far from the measurement point, or when we want to save in power measurement instrumentation.

The apparent powers of unbalanced and/or distorted subsystems measured using real grounding points as the voltage reference points instead of the neutral points of the subsystems contain errors, the magnitudes of which increase with increasing imbalance and/or distortion of the subsystems. Nevertheless, the errors can be avoided using Equations (37) and (39), presented in this paper, as demonstrated by the second and third application examples considered in the present study.

The Buchholz apparent powers of most power sources can be determined with great precision by measuring only the load powers and using Equations (25) and (27). This was also demonstrated by the first and fourth (real-world) application examples considered in our study. This procedure is based on the fact that the power source of an electrical system is usually less unbalanced and distorted than the load, and the neutral-displacement power of the former is, thus, not as influential as that of the latter.

Author Contributions: Conceptualization, V.L.-M., J.M.-R. and E.P.-L.; methodology, V.L.-M.; software, J.M.-R.; validation, V.L.-M, J.M.-R. and E.P.-L.; resources, V.L.-M, J.M.-R. and E.P.-L.; data curation, V.L.-M., J.M.-L. and E.P.-L.; writing—original draft preparation, V.L.-M.; writing—review and editing, J.M.-R., E.P.-L. and C.M.Á.-B.; supervision, V.L.-M.; project administration, E.P.-L. and C.A.-B.; funding acquisition, E.P.-L. All authors read and agreed to the published version of the manuscript.

Funding: This research was funded by Universidad Politècnica de València, under grant Primeros Proyectos de Investigación (PAID-06-18), Vicerrectorado de Investigación, Innovación y Transferencia de la Universitat Politècnica de València (UPV). The APC was funded by Universitat Politècnica de València.

Acknowledgments: The authors deeply thank the Universitat Politècnica de Valencia.

Conflicts of Interest: The authors declare no conflicts of interest.

\section{References}

1. Emanuel, A.E.; Orr, J.A. The effect of neutral path impedance on voltage and current distortion. PART I: Symmetrically and balanced three-phase systems. In Proceedings of the 11th International Conference on Harmonics and Quality of Power, Lake Placid, NY, USA, 12-15 September 2004; pp. 186-190. [CrossRef]

2. Emanuel, A.E.; Orr, J.A. The effect of neutral path impedance on voltage and current distortion. Part II: Imbalanced three-phase systems. In Proceedings of the 11th International Conference on Harmonics and Quality of Power, Lake Placid, NY, USA, 12-15 September 2004; pp. 180-185. [CrossRef]

3. IEC 60050-195:1998; UNE 21302-195/1M:2004. Electrotechnical Vocabulary. Part 195: Earthing and Protection against Electric Shock; International Electrotechnical Committee: Geneva, Switzerland, 1998.

4. Boyajian, A.; McCarty, O.P. Physical Nature of Neutral Instability. Trans. Am. Inst. Electr. Eng. 1931, 50, 317-327. [CrossRef]

5. Gates, B.G. Neutral inversion in power systems. IET-J. Inst. Electr. Eng. 1936, 78, 317-325. [CrossRef]

6. Gilkeson, C.L.; Jeanne, P.A. Overvoltages on Transmission Lines. AIEE Trans. 1934, 53, 1301-1309. [CrossRef]

7. Clarke, E.; Crary, S.B.; Peterson, H.A. Overvoltages During Systems Faults. AIEE Trans. 1939, 58, $377-385$. [CrossRef]

8. Concordia, C.; Peterson, H.A. Arcing Faults in Power Systems. AIEE Trans. 1941, 60, 340-346. [CrossRef]

9. Mortlock, J.R.; Dobson, C.M. Neutral earthing of three-phase systems, with particular reference to large power stations. IET-J. Inst. Electr. Eng. 1947, 94, 549-568. [CrossRef] 
10. Rocha, A.C.O.; Souza, W.M.; Mendes, J.C. Practical experiences in the analysis of abnormal voltages due to neutral instability. In Proceedings of the 2004 IEEE/PES Transmission and Distribution Conference and Exposition: Latin America (IEEE Cat. No. 04EX956), Sao Paulo, Brazil, 8-11 November 2004; pp. 952-958. [CrossRef]

11. Raunig, C.; Schmautzer, E.; Fickert, L.; Achleitner, G.; Obkircher, C.; AG-Austria, Ö.I. Displacement voltages in resonant grounded grids caused by capacitive coupling. In Proceedings of the 20th International Conference and Exhibition on Electricity Distribution (CIRED 2009), Prague, Czech Republic, 8-11 June 2009. [CrossRef]

12. Döring, L.; Braun, B.; Böhme, K.; Werben, S.; Kereit, M.; Hanson, J. Analytical calculation of the neutral point displacement voltage for high impedance earth faults in resonant earthed neutral systems. In Proceedings of the CIRED 2019 Conference, Madrid, Spain, 3-6 June 2019; ISBN 978-2-9602415-0-1.

13. Zulaski, J.A. Apparatus for Detecting Neutral Displacement of a Polyphase System. U.S. Patent US3859564A, 7 January 1975.

14. Premerlani, W.J.; Liu, Y.; Lavoie, G.P.; Pintar, M.G.; Zhou, R.; Papallo, T.F., Jr.; Valdes, M.E. System and Method of Locating Ground Fault in Electrical Power Distribution System. U.S. Patent EP1669767A1, 20 February 2007.

15. Konotop, I.; Novitskiy, A.; Westermann, D. Constraints on the Use of Local Compensation for the Correction of Neutral Voltage Displacement Caused by the Influence of Nearby Power Lines. In Proceedings of the 2014 Electric Power Quality and Supply Reliability Conference (PQ), Rakvere, Estonia, 11-13 June 2014. [CrossRef]

16. Kai, L.; Guojie, X.; Xiaojing, G.; Kun, Y.; Duohong, C.; Ran, L.; Fan, C.; Xiangjun, Z. Method for suppressing neutral point displacement overvoltage and suppression circuit in distribution network. In Proceedings of the 2018 China International Conference on Electricity Distribution (CICED), Tianjin, China, 17-19 September 2018; pp. 1726-1729. [CrossRef]

17. Harner, R.H.; Owen, R.E. Neutral Displacement of Ungrounded Capacitor Banks During Switching. IEEE Trans. Power Appar. Syst. 1971, PAS-90, 1631-1638. [CrossRef]

18. Funk, G.; Kizilcay, M. Limiting of neutral displacement voltages in power systems with arc suppression coils in case of unbalanced system capacitances to earth. Etz Arch. 1988, 10, 117-122.

19. Li, J.; Wan, X.; Sun, C. Discussion on abnormal rise of displacement voltage of neutral point in compensation electric network and its control measures. In Proceedings of the 2006 International Conference on Power System Technology, Chongqing, China, 22-26 October 2006. [CrossRef]

20. Buchholz, F. Die Drehstrom Scheinleistung bei Ungleichmas-siger Belastung Der Drei Zweige. Licht Und Kraft 1922, 2, 9-11.

21. León-Martínez, V.; Montañana-Romeu, J. Method and Device for Determining the State of the Neutral Conductor in an Electrical Installation. Spanish-Granted Patent ES 2588260 B2, 9 May 2017.

22. IEEE Std. C62.92.5. IEEE Guide for the Application of Neutral Grounding in Electrical Utility Systems, Part $V$-Transmission Systems and Subtransmission Systems; IEEE: Piscataway, NJ, USA, 2009.

23. IEEE Standard 1459 2010. IEEE Trial Use Standard for the Measurement of Electric Power Quantities under Sinusoidal, Non-sinusoidal, Balanced or Unbalanced Conditions; IEEE Power and Energy Society: New York, NY, USA, 2010.

24. Emanuel, A.E. Power Definitions and the Physical Mechanism of Power Flow; IEEE Press: Piscataway, NJ, USA; John Wiley \& Sons Ltd.: Hoboken, NJ, USA, 2010; ISBN 978-0-470-66074-4. [CrossRef]

25. Czarnecki, L.S. Currents' physical components (CPC) in circuits with nonsinusoidal voltages and currents. Part 2: Three-phase linear circuits. Electr. Power Qual. Util. J. 2006, 12, 3-13.

26. Czarnecki, L.S. Orthogonal decomposition of the currents in a 3 phase non linear asymmetrical circuit with non sinusoidal voltage source. IEEE Trans. Instrum. Meas. 1988, 37, 30-34. [CrossRef]

27. Akagi, H.; Watanabe, E.H.; Aredes, M. Instantaneous Power Theory and Applications to Power Conditioning; John Wiley \& Sons, Ltd.: Hoboken, NJ, USA, 2007.

28. Kim, H.; Blaabjerg, F.; Bak-Jensen, B. Spectral analysis of instantaneous powers in single-phase and three-phase systems with use of p-q-r theory. IEEE Trans. Power Electron. 2002, 17, 711-720. [CrossRef]

29. Willems, J.L.; Ghijselen, J.A.; Emanuel, A.E. The apparent power concept and the IEEE Standard 1459-2000. IEEE Trans. Power Deliv. 2005, 20, 876-884. [CrossRef]

30. Cazorla-Navarro, A.; Garcia Giner, J.; León-Martínez, V.; Montañana-Romeu, J. Procedure for the Measurement of Powers, Energies and Efficiency in electrical installations, and the device thereof (in Spanish). Spanish Granted Patent ES 2166670 B1, 16 February 2003. 
31. Fortescue, C.L. Method of symmetrical coordinates applied to solution of poly-phase networks. In Proceedings of the 34th Convention of American Institute of Electrical Engineers, Atlantic City, NJ, USA, 28 June 1918. [CrossRef]

32. Chroma ATE Inc. Chroma Programmable AC Power Source 61700. User's Manual. Available online: https: //www.chromausa.com/product/3-phase-programmable-ac-source-61700/ (accessed on 28 January 2020).

33. Advantech Co. Ltd. Processor Board PCM-9581. User's Manual. Available online: http://advdownload. advantech.com/productfile/Downloadfile4/1-124ET90/PCM-9581_user_manual_Ed2.pdf (accessed on 28 January 2020).

34. National Instruments Corporation. Data Acquisition Board PCI-6220. Available online: https://www.ni.com/ documentation/en/multifunction-io-device/latest/pci-6220/overview/ (accessed on 28 January 2020).

35. LEM Transducers. Voltage Transducer LV 25-P. Available online: https://www.lem.com/en/lv-25p (accessed on 28 January 2020).

36. FLUKE. AC Current Clamp i5sPQ3. Available online: https://www.fluke.com/es-es/producto/accesorios/ pinzas-de-corriente/fluke-i5spq3 (accessed on 28 January 2020).

37. De Lorenzo, S.p.A. Resistances DL1017R. Available online: https://www.delorenzoglobal.com/image/powerengineering-modules.pdf (accessed on 28 January 2020).

(C) 2020 by the authors. Licensee MDPI, Basel, Switzerland. This article is an open access article distributed under the terms and conditions of the Creative Commons Attribution (CC BY) license (http://creativecommons.org/licenses/by/4.0/). 